\title{
Porn 2.0 Utopias - Authenticity and Gay Masculinities on Cam4
}

\author{
PATRICK HENZE (PATSY L'AMOUR LALOVE) - Humboldt University, Berlin
}

\begin{abstract}
The article discusses how the pornographic desire for authenticity is realised on porn 2.0 websites like Cam4. Against this background the analysis focuses on gay masculinities and their representational politics within gay mainstream pornography. Gaying, as the tradition of staging a utopian gay world without discrimination, as well as porning, the possible transformations of gay subjectivities through porn, are presented as central concepts of gay pornography. The author connects recent developments of online pornography with analytical approaches of Linda Williams' Porn Studies and locates porn 2.0 in the trajectory of gay pornography.
\end{abstract}

KEYWORDS: Porn Studies, Gay, Masculinities, Authenticity, Body Politics, Cam4, XTube, Porn 2.0

\section{Porn Studies}

1989 can be set as the birth date of Porn Studies, when Linda Williams published her work Hard Core. She traces traditions within heterosexual hardcore pornography and how movies like 'Deep Throat' (1972) had the power to seduce masses of people into crowded porn cinemas. The timing of Hard Core's publication is significant in that the feminist Sex Wars in the USA divided the movement between those fighting for strict censorship of every type of pornography and those countering such an effort as dogmatic. For Williams, pornography is not analyzed with the intention to show its morally diseased and/or misogynist character. Rather, Williams's work points out the importance of understanding pornography as a complex social phenomenon consisting of a massive amount of medial products that can be seen as a representation of society's patriarchal character and that also can arouse women or even have empowering effects (. Williams 1995, 30). Antipornography feminists claimed that if a woman is aroused by pornography, she is either a concrete victim of patriarchy or its accomplice. From this standpoint, there was no need to analyse pornography in similar ways to other non-pornographic texts, because every pornographic depiction was seen as an oppressive of women - even all-male moving image porn (Dworkin 1987, 122-142 and MacKinnon 1993, 25 for an anti-pornography perspective; see Green 2000, 32f for an analytic approach to this standpoint).

Situating an approach in the tradition of Porn Studies - as I do with this article - therefore means specific political implications: It is not to be seen as a genre reinforcing moral disease, yet it is important to consider how porn has 'either aroused so much animosity or has been made ridiculous 
to such an extent, that it seemed to exclude every serious analysis.' (Williams 1995, 32) ${ }^{1}$ Pornography therefore is seen as one genre amongst others, with its own specific traditions of representation and its distinct historical developments.

Williams states that pornography produces utopias, calling them 'pornutopias' (Williams 1995, 203). According to this concept pornography produces realms of imagined realities as solutions for (the protagonists' or the staged societies) problems, especially through its effort to show 'real' sex for its consumers (Williams 1995, 204f). This aspect is a central within Porn Studies approaches to gay pornography. As pornography as 'authentic' affects desires within other 'real' spheres of gay men, its influences on these spaces have been analyzed. For example Richard Fung states that racism within gay mainstream pornography is reproduced by staging racist hierarchies, as it produces structures of marginalisation by showing sexual(ised) acts of racial inequality (Fung 1999, 518). Riche Cante and Angelo Restivo claim that gay porn can and does even transform gay spaces - this will be central in my considerations below (Cante/Restivo 2004, 144).

\section{Queer Media Studies}

In its critical and explicitly political as well as transdisciplinary approach, Porn Studies can be directly linked to Gender and Queer Studies and its research on media, or more specifically Queer Media Studies. I want to briefly point out two central aspects of the latter directly related to my analysis. In her research on representational politics regarding queer characters in horror and science fiction movies, Uta Scheer highlights that movie texts cannot only be seen as informational representations but are always set into broader sociopolitical dimensions (Scheer 2009, 243). ${ }^{2}$ Therefore a queer analysis of medial products has to focus on the politics of visibility and bear in mind the societal context in which movies are produced and thereby be one 'that outreaches individual psychological interpretations. ${ }^{3}$ (ibid 2) Implicitly this refers to an approach to medial products specific for Queer Media Studies. Douglas Kellner claims that there is no 'innocent entertainment' (Kellner 2001, 9) because it always affects real spaces and therefore not only produces its characters and plots, but in some way also creates parts of our realities. Therefore movie output includes not only entertaining moving images. In fact it is interconnected to its viewers: movies themselves partially become outputs of the viewers' desire and, by taking up and repeating desired images, impacts the viewers' desires.

Firstly this means that the analysis of gay pornography has to be aware of societal aspects and concrete gay realities. In this way it pays attention to the fact that gay lives - in their vast variety of forms often share different kinds of experiences compared to heterosexuals; meaning diverse kinds of discrimination as well as all the (infrastructural) shapes of gay communities. Against this background the medium can be examined through its direct and complex interdependency to its audience. Specifically gay desires, marked by specific implications relating to their standing within a heteronormatively dominated society like Germany or the USA, are done by 'real' gay men as well as reenacted and made by gay pornography. ${ }^{4}$

1 Translated by Patrick Henze. In the German edition: ' so viel Feindseligkeit hervorgerufen hat oder so sehr ins Lächerliche gezogen wurde, daß es jegliche ernsthafte Analyse auszuschließen schien.’

2 In this approach she refers to Critical Cultural Studies and John Fiske (. Fiske 1996).

3 Translated by Patrick Henze. Original text: „die über individualpsychologische Interpretationen hinausreicht.'

4 My analysis might seem to ignore the influence of mainstream porn industry's relations of production. In fact, this aspect will only play a marginal role in my article. However, what I claim to be a complex interdependency is part of these relations of production, as they at least partially determine what is wanted, paid for and therefore produced. 


\section{Objectivity and Involvement}

Situating myself within as well as coming from Gender Studies via a trans-disciplinary approach, after the introduction to my presupposition on the topic, my individual queer perspective shall be made visible to make my research more reflexive. Hereby I follow feminist theorists like Paraskevi Taki, Marjorie L. DeVault and Glenda Gross or Kaysi Eastlick Kushner and Raymond Morrow mentioning reflexivity as one of the most important markers for the conglomerate called feminist theory (Taki, 2; DeVault/Gross 2006, 178; Kushner/Morrow 2003). Thereby from a feminist perspective, scientific objectivity can be defined in a contrasting way to its traditional understandings. As Kerstin Palm puts it, inspired by Sandra Harding, strong objectivity 'is marked by self-reflection plus, directly connected with it, a democratisation. ${ }^{5}$ (Palm 2007, 154)

Being gay and therefore partially socialised within German gay (sub)cultures, I have other connections to gay pornography than, for example, most self-defined heterosexual men would have. Within gay spaces you will find a mass of references to pornographic and sexualised imagery and infrastructure. My personal connection is partially made through this position and all-male action, male bodies and identities are what fall into my realms of desire. In this sense I want to continue Williams' thought when she explains, why her focus lies on straight pornography. For her, individual identifications and desires become central to how we analyse media - especially when, like in gay porn, you can figure out an obvious and strong target audience orientation. Therefore she underlines that it can make sense to concentrate on the medial products you can relate to regarding desire as well as identitie(s) (Williams 1995, 30). For the analysis this means a visualised standpoint and marker for not pretending to have an objective view on gay pornography in the sense of a nonexisting researching subject, but to be objective in the sense of reflexivity.

As a gay activist working within the queer movement and accounting for the contexts in connection to my Gender Studies approach considered above, I make the political character of my effort develop. Germany or the USA, are structured heteronormatively to include that homophobia as a basal element of their shape (Henze 2012, 40ff). Correspondingly, to make gay subjectivities visible and to deal scientifically with gay subjectivities there are possible modes of encountering homophobia. ${ }^{6}$ The analysis of how non-heterosexualities are set within (also non-heterosexual) media is one instrument for it, or, as Scheer puts it more pointedly:

'Especially in the face of the fact that people still experience discrimination, violence and material disadvantages in their everyday lives because of their non-heterosexual (respectively transgender) identities and that difficulties due to heteronormative structures are not a thing of the past at all, this allusion to the interdependency between representations of non-heterosexual identities and real life shall not be underestimated.'7 (Scheer 2004, 294)

5 Translated by Patrick Henze. Original text: ,zeichne sich durch eine SelbstReflexion sowie, unmittelbar damit zusammenhängend, eine Demokratisierung aus.'

6 According to Gabriele Dietze's, Elahe Haschemi Yekani's and Beatrice Michaelis' sense, queer subjectivities comprise for instance „Queer Theory, queer activism and sexualities' (Dietze and others 2007, 111; translated by Patrick Henze. In the original text: 'Queer Theory, queerem Aktivismus und queeren Sexualitäten'). In this sense I understand ,gay subjecitivities' as an interdependent fusion of various and diverse aspects of gay lives.

7 Translated by Patrick Henze. In the original text: 'Gerade angesichts der Tatsache, dass Menschen aufgrund ihrer nicht-heterosexuellen (bzw. trans-geschlechtlichen) Identitäten immer noch Diskriminierungen, Gewalt und materielle Nachteile im Alltag erfahren und Schwierigkeiten aufgrund heteronormativer Strukturen alles andere als der Vergangenheit angehören, sollte dieser Hinweis auf die Wechselbeziehungen von Repräsentationen nichtheterosexueller Identitäten und realem Leben nicht unterschätzt werden.' 


\section{Questions}

Besides my own research on Porn Studies, my background knowledge refers to current gay mainstream porn movies as well as the classification of around 500 Super 8 movies from the 1970s in the archives of the Schwules Museum in Berlin. In this part of the article I will point out traditions of gay pornography related to gay masculinities and the desire to see 'authentic' sexuality. Therefore I will introduce the concepts of 'gaying' and 'porning'. Gaying can be read as an effect of what gay sexualities did to pornography. It gave marginalised gays the space to develop a pornographic utopia of sexual freedom and pride. Porning is the main effect of the complex interdependencies between production and viewing. Through the intention to show authentic sex and the desire to identify with these pornutopian, gayed settings, gay mainstream pornography shapes gay spaces, bodies and the view on ourselves. I will then deal with Cam4 as an influential Web 2.0 porn community, or, Porn 2.0. First of all Cam4 shall be consulted as a community of desires and therefore will be examined through how gay desires, identifications and masculinities are staged and (re)formulated on the website - how Cam4 is being gayed. Then I will consider the psychological effects of authenticity and how Cam4 sustains its staging in a multi-personal involvement. It also has to be asked, how this specific gaying looks and in what way Cam4 is porning gay masculinites.

\section{Gay Pornography: Pornutopia and Normalisations}

\section{Moving Histories}

Reflecting on the cultural effects of gay porn aesthetics and its traditionalised modes of staging, Cante and Restivo observe a historical concomitance 'The emergence of feature-length hard-core pornography in the United States occurred in the relatively fresh wake of the Stonewall rebellion' (2004, 144). For them, as well as for Jeffrey Escoffier $(2009,6)$, this is no coincidence and cannot be seen without a connection to the particular implementations in the genre and the emergence of gay liberation movements. Besides these interdependencies caused by their historical coexistence, I share Cante's and Restivo's suggestion that there is a close correlation between gay porn and gay movements, for example in terms of visibility. 8

Escoffier (2009) outlines the importance of cinemas for US gay porn's development in the 1960s and 1970s. During this time adult cinemas were a popular spot for men seeking all-male action. Gay movie erotica as well as erotic magazines did not consist of hardcore action, but of scantily clad men flexing and posing (ibid. 16-20). Escoffier sees San Francisco as the first city where gay hardcore pornography was screened - in over 25 porn theatres - in the watershed year of 1969. For him, these porn theatres 'defined a new gay sexual culture. Participation in the sexual scene gave gay men a chance to learn about sex and about other gay men in a public setting rather than in more furtive personal encounters' (Escoffier 2009, 91) In this sense pornography functions as sexual education, conveying a lustful relation to gay sexualities to its viewers.

In 1971, Wakefield Poole presented his feature length movie Boys in the Sand in New York. On the one hand it affected a large interest so that not only homosexuals came to watch the movie. But on the other hand, it was also disruptive of gay men's cruising habits as it did not just show all-male action but also stills of landscapes and many non-sexual sequences. In his 'Photographic Journey'

8 In his book 'Armee der Liebenden oder Aufstand der Perversen' from 1979 in which he searchs for traces of early gay movements in the USA, Rosa von Praunheim interviews porn star Fred Halstead. He sees himself as a gay icon for gay visibility as well as inflated ideas of masculinity. Praunheim, as a movement sister of the time, therefore saw pornography and its stars as an important part of gay resistance culture. 
of gay mainstream pornography, Kevin Clarke (2011) however emphasises the movie as the first gay porn that can be called a blockbuster and therefore gay mainstream pornography. One year before Deep Throat (1972) it established modes of staging that shall become typical for gay mainstream pornography (ibid. 55). It was the first movie showing all-male sex as a dreamscape of gay lust and thereby creating a utopia, 'a laid-back look at how gay life might be one day: free and fabulous and fulfilling, sexually at least' (ibid. 54) For most of the men in the audience this was the very first time they had seen gay sexuality presented as something positive and identifiable in a semi-public (and not exclusively gay) setting. 'Pornography', as Escoffier puts it, 'created a space for increased experimentation with a whole range of sexualities not organised around procreation and reproduction' (Escoffier 2009, 5).

\section{Gaying Spaces}

As I illustrated historically, gay mainstream pornography was (and is) able to give gay men a sense of their sexuality. In addition, Cante and Restivo remark, that 'pornography remains the one genre where, in numerical terms, gayness is unquestionably much, much more commonly represented than in any other category of U.S. moving-image product' $(2004,147)$. This does not only relate to the characters of gay porn movies. Furthermore the gayness of the action leads to a gaying of the characters as well as the spaces in which their actions take place. Cante and Restivo mention space as a central topic in the production of gay porn in contrast to non-gay pornography and relate this specific importance to the hetero-normative character of the hegemonic separation into private and public spheres $(2004,142$; ibid. 148). In this sense spaces that are publicly, semi-publicly or partially publicly accessible, exclude characters and actions being openly gay as they would gay these spaces and - more dangerously - the other visitors. Remarkably those spaces known as arenas of hegemonic, homophobic masculinities are the ones you will find as settings of gay porn movies such as barracks, changing rooms or jails. These spaces are also aligned to public spheres in such as streets, schools and university buildings, where usually homosexuality would be marginalised or even sanctioned. Along with these spaces, Cante and Restivo also remark that gay porn is 'gaying' itineraries of everyday life.' (ibid. 147) These itineraries include for example a consultation at the doctor's, calling a plumber, ordering a pisza which can then turn into a sexual adventure and/or encounter.

Porn Studies' thesis of pornutopias considers this depiction of gay pornography. Whilst in 'real' life, there is a marginalisation of gay sexualities and identities, these movies stage wholly gayed settings where fear is turned into lust, or, where taboos of sexualisation - for example getting aroused by your hair-dresser and making out with him - combined with the feeling of being the only gay around, transform into gay sex as the only possible solution of the situation. The pornutopia then is 1) the gay conquest (what gaying is all about) of heterosexually and homophobically dominated spaces and 2) to device that disrupts the taboo of homosexuality (in every occasion) and sexuality in general vis-a-vis questions of public/private spaces and situations. In Cante's and Restivo's words 'After all, in its continual reinscription of all the spaces surrounding us, all-male pornography at some point also becomes the field for the (utopian) reinvention of the world eternally promised by identity politics.' (ibid. 143).

\section{Porning Gays}

Gay porn can be the phantasmatic realm of gay utopias and effect private and intimate revolutions through its recipient. However, the mainstreaming of gay porn including the emergence of a gay porn industry also leads to the development of certain staging and representational traditions that bear normalising effects. For the analysis this means we have to consider the quantity of gay 
subjectivities in the movies and how they are depicted. It is not just gay utopias created by gay porn but in some aspects how the utopia can become a restricted field of fixed definitions within identifications of gay, sexy, beautiful or desirable.

Within the genre gay porn there are subgenres which have their own niche markets such as bears ${ }^{9}$, dirty, rubber and BDSM, twinks and hunks ${ }^{10}$. In an adequate analysis the latter shall be distinguished and not be called 'subgenres'. Gay porn subgenres can be classified by an otherness in regards to movies not being labeled, for instance 'bears' or 'BDSM'. Following Chris Brickell, what is hegemonically defined as the norm is mostly invisibly visible as its non-appellation in contrast to the marking and naming of non-normativity, in turn this creates a semantic sphere of an unquestionable, nature-like normality (Brickell 2000: 165f). ${ }^{11}$ In this sense twinks and hunks present the normative idea of beautiful male bodies within gay contexts and non-BDSM and nondirty sexual practices stand for the conception of generally desirable or normal sexuality. Through the constant repetition of the same bodies and the elision of non-normative sexual practices, gay pornography picks up concepts of beauty and normality from the contexts of gay community and produces a certain 'gay taste', thereby normalising it by its own classifications of some movies into subgenres.12 By understanding gay porn as an influential medium in regards to gay subjectivities, I also refer to Cante and Restivo when they state normative body images and desirable 'gay lifestyles' presented in the movies will effect that,

„gay men will indeed transform themselves - not just by working out but also by shaving their genitalia and torso, getting certain haircuts, growing facial hair in certain patterns, purchasing particular types of swimwear, picking up certain phrases and tones of voice, and so on - so that the spaces they actually traverse will effectively begin to conform more and more closely to that which is the proper representational ground for their own manufactured images.' (Cante/Restivo 2004, 144)

In this sense gay mainstream pornography affects 'real' gay spaces and lives. Somehow body representations and the way that gay sex looks like becomes close to its pornographic staging. Porn does not only reproduce what its recipients desire to see, but also produces their desires. Against this background, Fung's analysis of the reproduction of colonial perspectives on racially othered characters in gay porn movies highlights the sociopolitical dimension of understanding pornography. For him, the iterantly staged idea that 'a person (...) seen as Japanese and somewhat kinky, or Filipino and 'available' $(1999,518)$ can influence the real lives of Asian gay men, their sexualities as well as their sense of self.

This interdependency of gay porn and its viewers led to the terminology of porning, whereby I suggest that processes of influence on gay subjectivities are (at least partially) produced by porn

9 „Bears' is a term for gay guys with bodies not fitting in the normative idea of beauty within gay contexts, what concretely means athletic, muscular or skinny bodies with shaved or cropped bodyhair.

10 Twinks are juvenescent characters, mostly with shaved bodyhair while 'hunk' stands for stereotypically masculine men with muscles and sometimes body hair.

11 This can be exemplified by the phenomenon that 'a couple' is mostly used in reference to a heterosexual couple whereas a gay couple seems to need the 'gay' to be exact. Heterosexuality as a definition becomes invisible but nonetheless the dominant marker.

12 In her analysis on body images of gay advertisement, Rosalind Gill remarks that the repeating depiction of always the same or almost the same bodies leads to a specific taste or normative view on gay beauty. which she puts graphically: 'The models are generally white, they are young, they are muscular and slim, they are usually cleanshaven (with perhaps the exception of a little designer stubble), and they have particular facial features which connote a combination of softness and strength - strong jaw, large lips and eyes, and soft looking, clear skin.' (Gill 2009, 144) 
movies. It is inadequate to make porn 'responsible' for normative body images and racist structures in gay communities and this is not what I want to state in my analysis. For me it is important to pull (gay) porn out of its socially ineffectual image and highlight discursive, psychological and sociopolitical structures and interdependencies within this highly seductive and demanded product. To call gay porn a realm of utopias and its pornutopias realms of gay freedom in this sense covers the fact that the restrictions of what is shown as desirable, beautiful and normal to a wider audience. There is a both a sense of freedom in the exclusiveness of gay pornography, just as there are exclusions and marginalisations. By gaying the world around us it can happen that porning gays does not only transfer the private sexual revolution into real life but also the claim to fit to this world's own normative images.

\section{Cam4 - Approaching a Porn Phenomenon}

Pornographic web 2.0 websites, called porn 2.0, gave people the chance to upload their homemade porn clips, watch those of others, get friends to other porn 2.0 users and create online porn communities. Amateurs producing porn were the answer to an audience sated by 'plastic porn' that could not fulfill the demand for real, authentic sex. Shaking hand cameras and pixelated webcams became a sign for this realness and authenticity. After XTube, where video clips can be watched and uploaded, Cam4 gave the chance for individuals to present themself live via webcam as well as to spend time watching them. Everyone using the internet and a webcam can show him/herself to a worldwide audience. Basically the website is for free, but there is the possibility to give tips, win a prise for the best or most popular cam of the month and to turn to (paid) private chat rooms via other webcam applications. Cam4 forms a porn 2.0 community where you can interact by chatting, screening, connecting profiles or commenting.

In her partially polemic essay 'Porn Chic im Web 2.0 Zeitalter' presented at the queer porn conference 'symposium pornonom' in Vienna 2009, Katherina Zakravsky discusses the development of (especially gay) porn. For her, porn 2.0 websites 'herald the biopolitical era of postnormed human specialisation' and function as an 'anarcho-dilettante freakshow' (Zakravsky 2009, $6)^{13}$. While also remarking that there can be normalising modes of staging within or by the vast variety of representations, Zakravsky remains enthusiastic about porn 2.0; perhaps too enthusiastic. In the following I want to concretise this intervention and carve out the phenomenon of Cam 4 with my delineated questions by contextualising it through liberating as well as normative factors.

\section{Community of Desires}

As mentioned above, one of Cam4's specific characteristics in comparison to other web 2.0 platforms means its pornographic bias and the web 2.0 feature can be stated as its difference to most pornographic websites. The website forms a porn oriented online community by the option to interact and to consume, produce or comment on porn. The modes of communication are structured by the website itself. This structure includes for example gender categories and ratings. Opening the website you will have to confirm your age and your acceptance to watch adult material. After consenting, the interface gives a summary of the most popular online webcams from all available main categories. These are 'Female', 'Male', 'Couple', 'Transgender' and 'Party' (Cam4 2013). Within the first four categories a monthly winner gets elected for the most viewers. The prise money in summary accounts $\$ 15,000$ US Dollars. As 'Contest Rules' you will find brief notes on how to categorise yourself correctly:

13 Translated by Patrick Henze. In the original text: „Porno wird hier anarcho-dilletantische Freakshow und läutet das biopolitische Zeitalter der post-normierten Humanspezialisierung ein. Wenn hier noch jemand einen anderen brutal ausbeutet dann nur noch der Kameramann/Darsteller sich selbst.' (Zakravsky 2009, 6) 
'Female Cam - Only single females. Male Cam - Only males. Can be male/male and groups of males. Couples Cam - Can be female/male ; female/female; and groups of female/male. Shemale Cam - Must be a shemale, transsexual, hermaphrodite, or transvestite (cross-dresser) on cam. (...) Cheaters will be disqualified.' (Cam4a 2013; emphasis in original)

If you can fit to these rules and are willing to distribute your live show to Cam4, you will appear available in the particular category. But even if you do not want to show yourself, your profile will be findable for everyone in the online community. The profile consists of photos, the place where you present your body features, age, favorite sexual practices and the possibility for others to leave a comment on the page. The users can link others' profiles - add friends - and send each other messages. Under the category 'Male' the most popular cams in means of viewers quantity are shown by cam stills, profile name, nationality, sexual orientation, screening duration, amount of viewers and individual headline. Opening an online profile with screening webcam, the interface presents the two biggest parts of the window formed by webcam and the chatroom (see Picture 1). As a viewer you can chat with the model and the other viewers, and send tips to the actor. 100 tips $=$ $\$ 10$ US Dollars and here $62.5 \%$ belongs to the webcam model (Cam4b 2013). Regarding the interaction, this means you can show yourself, chat, watch other webcams and (potentially) get paid or you can observe and chat without being watched yourself.

Through the masses of cams and profiles available, the possibilities of interaction, the simple system of earning money as well as the (at least seemingly) democratic nomination of monthly winners are central aspects of what makes Cam4 appear 'authentic'. Williams states that porn movies and their sequences stage pornutopias. The browsing on websites like Cam4 can itself be seen as using porn media. The pornutopia then is not only created within the webcam screenings, but by the digital space Cam4 produces. This space involves its users directly in these various ways. This experience of pornography blurs the lines between actors and viewers as well as the media itself. While the webcam screenings as well as the user accounts have to be seen as stagings, in a pornographic and web 2.0 sense they function as 'real' sex and persons to be connected with. Against this background by creating an account, users build up a digital character by becoming friends with others that shape community and internal identities. Consequently, the central aspect is self-expression and thereby rating and valuing, getting rated and valued. The most efficient way to do this is to comment on profiles and webcam shows - these comments can be seen in the wide range of ways from praise to insult.

Cam4 as a community is formed through a sphere of narcissistic relation to oneself and the other(s), where digital and real life are connected and overlapping through users. Here it becomes unclear if it is a voyeuristic or an exhibitionist desire being satisfied. In browsing and being browsed, watching, showing and being watched desirable bodies and identities are being searched, sometimes found (for some instances) and then rejected again. This pursuit of narcissistic digital self-esteem can be materially connected through masturbation and arousal in front of the screen - porn 2.0 directly shows porn's relation to the inseparability of desire and identification when it is not clear any more if the viewer gets aroused by another person/actor, him/herself or both, messages and communications or a fluid combination of these porn 2.0-factors. While identification stays latent within the (browsing for) desire to one another, desire seems to be the manifest connecter of Cam4's community. To earn money therefore can be one reason to become a member but obviously does not become the main intent.

What might be shown by these considerations is how the direct link from medial product to its audience is fragmented due to porn 2.0. To distinguish audience, producers and actors becomes 
virtually impossible and definitely less important. The narcissistic element of Cam4 creates a digital sphere of (self-)identification including not 'only' actors on a screen, but involves the self in various ways and immediately associated with (self-)desire. You can get off by being watched - by yourself and others - or by chatting and watching, imagining and not least believing that what you see is live and therefore 'real'.

In this way, Cam4 fits within the trajectory of amateur pornography as a booming market within the porn industry. ${ }^{14}$ Cam4's appearance has not changed much since first appeared in 2007, which means that its amateur charm has been sustained. Yet the modes of paying and earning have been professionalised considerably. This can be explained by the intended image as an amateur website where every 'exhibitionist, with or without experience' (Cam4c 2013) is welcome to present $\mathrm{him} / \mathrm{herself}$. At the same time, the makers point out their own professional experience as 'a dedicated team of industry veterans' working with a 'combination of knowledge and passion' (Cam4 2013). The sense of an amateurish porn website where you can actually interact with the actors gives a recent answer to what also Williams described as a combination of knowledge and passion. For her this also means a passion for knowledge about sex, the desire to know everything about and see every detail of what $i$ s sex (Williams 1995, 25). Personalising Cam4, it gives the promise to its audience not to show 'fake' porn but to finally disclose every secret of sexuality kept within private or intimate spheres before.

In fact, Cam 4 and porn 2.0 has to be analysed in relation to feature length gay mainstream porn movies on DVD and the internet as well as short cut clips. Also Cam4 as a webcam porn website has to be distinguished from those porn 2.0 platforms not including webcam screenings. But it does make sense to range Cam4 into gay mainstream pornography - amongst others. Cam4 takes on staging traditions of gay pornography such as the fulfilling of passions for knowledge by its high degree of performed authenticity. At the same time it is important to bear in mind the performative character of the webcam screenings and the web 2.0 surrounding as it is always a consciously controlled presentation to the outside world and the interaction happens on a digital interface. To queer authenticity in this sense is a question of epistemological positioning: While it is arguable if there can even be something defined as authentic at all, the idea of a staged authenticity in regards to webcam porn 2.0 has to be fundamental for an adequate analysis.

\section{Diversity and Representation}

Coming back to Zakravsky's statement on porn 2.0 and its subversive and revolutionary potential, it might be true that websites like Cam4 lead to an individual empowerment in front of the screen or even a Cam4-community based subversion of heteronormative ideas of normality in regards to sexualities and identities. This refers to the idea of a strict separation between public and private, the hegemonic degradation of certain sexual practices, bodies or identities and the basic societal structure of capitalist access to bodies and their functionality. In fact, such an internet revolution is not happening and not even in progress. Thinking of diversity as one part of liberating processes for LGBT, Cam4 and its vast amount of available webcams and therefore bodies and sexual practices can be seen as a field of representational freedom. At the same time, this freedom is set within very specific rules and a structure of categorising and valuing. The rules of who is what in regards to gender is rather interesting from various points of view. Women can show themselves only alone, otherwise they are defined as 'Couple' while men will be 'Male' either single, coupled or in groups. Two men are not allowed in the 'Couple' section, while every gender subsumed to 'Transgender' or

14 For a closer analysis on this aspect see Feona Attwoods article 'Younger, paler, decidedly less straight'“ (Attwood 2010) 
'Shemale' is excluded from 'Male', 'Female' and 'Couple'. ${ }^{15}$ Hereby for example trans*male identified trans*persons get excluded systematically if their wish is not to be subsumed to 'Male'. Again spotting the category 'Male' and the exclusion of male couples from 'Couple', all-male pornographic action is not only invisibly visibly marked as cis-gendered16, but also strictly separated from every other category. Mainstream pornography being dominantly drifted by heterosexual desire can be one possible explanation for this circumstance. In this sense Cam 4 accommodates heterosexual men's (unconscious) resistance to the confrontation with (own) homosexual desires. ${ }^{17}$ Within the category 'Male' many different bodies and sexual practices can be found. This is remarkable insofar, as mentioned above, gay mainstream pornography sets normative ideas of beauty in regards to the actors that, for example, include an age of between 18 and 40 or a body range from slim to athletic and muscular. Browsing the male webcams, you will find quantitatively more of those men not fitting into this pornographic stereotype. The representational diversity may fit more to actual gay realities.

Quantitatively diverse it is important to remark how the category's webcam selection is presented. Its order relays on the popularity of each cam, stated by the number of its viewers. Looking at the cams on top of the list, the mentioned diversity of bodies and practices disappears. There again you will find the 18 to 40 year olds and the slim to athletic and muscular bodies - the hunks and the twinks. Given the thesis that there is a normalised and therefore hegemonic gay taste in men, this is no coincidence but a representation of how porn 2.0 reproduces normative views on (gay) bodies and their thinness or sexual practices and their normality. ${ }^{18}$ Again the question shall not be how many but how gays are represented. One factor of such representational politics is the structure allowing certain modes of staging, excluding others and implicitly but obviously setting who is showed at the front line and who has to be browsed for. Even though Cam4 gives the possibility to everyone over 18 (with internet and a webcam) to show him/herself, systematically not everyone is seen in the same way. Following Cante's and Restivo's thesis for gay mainstream pornography that gay men will 'transform' themselves partially influenced by ideas of beauty represented by the actors, the way in which these men transform is not automatically being changed by Cam4 but may even be intensified when a higher grade of authenticity is assigned to porn 2.0.

\section{Private Insights - Public Avowals}

While the porning of gays through Cam4 may function slightly differently than gay mainstream porn movies but has similar effects, considerations of the gaying of spaces has to track the website's specific difference to feature length films as well as to (short cut) internet porn. Following the logic of Cam4's staging, the spectacle of the screenings lies within the exposed gayed private spheres to an audience perceived as public. While a feature length gay porn playing in a barrack constructs fascination to a high degree on a space usually dominated by heteronormative and therefore antigay masculinities, in live gay webcam screenings it is the private insight to someone's living space apprehended as an intimate and (partially) therefore arousing moment. There is tension in feeling

15 Interestingly on the main site the category is called „Transgender' while the rules talk of „Shemale' (. Cam4 2013; Cam4a 2013). This may be a hint to the dominance of female-associated trans*persons compared to male trans* in mainstream pornography.

16 'Cis-gender' refers to people living in the gender identity given to them after birth.

17 For a pointed psychoanalytic approach on how heterosexual male subjects act out homophobia see Andrea Trumann's essay on civic male subjects (. Trumann 2004).

18 Referring to Fung's analysis on whitely dominated gay mainstream pornography, you have to state that for Cam4, this is only partially true. In reference to the presented nationalities of each webcam under the category 'Male', North America, South America and Western Europe countries dominate the setting. This means African and Asian countries are not equally numerously covered on the website. The white and US as well as Western Europe dominated state of gay mainstream porn is somehow undermined by the vast number of South American webcams. 
private(ly connected to someone) in a sphere you think of as public. Cam4 and its actors here stage a sphere of authenticity, where private persons seem to allow private insights and share intimate moments. In fact these insights are staged and planned - as the actors are in control on how and what they present, for example which sounds are (not) included, how they act or when they close the connection. While I will highlight the aspect of authenticity itself, at this point my considerations on it shall help understanding the functionality of porn 2.0 and Cam 4 in regards to its audience. For the viewers, what they see, is in fact presented as a perceived 'reality of sexuality'. The staging modes and its effects on the users of Cam4 have to be approached against this background. In the following I want to highlight on three aspects of interdependent relations between medium and viewer, that shall firstly discuss the separation of public and private spheres, secondly (as well as inseparably connected with the fist point) the marginalisation of gay sexualities and thirdly on self-representations not being definable as exclusively emancipatory.

Cante and Restivo claim that 'distinguishing between public and private are hetero-normative from the start' $(2004,148)$. In this sense definitions of the public always include exclusions of what is not adequate in these spaces and shall be done in private (if anything at all) whilst especially queer subjectivities are being sexualised and therefore repressed into private spaces. This separation is culturally and historically arranged to make morally unaccepted desires invisible or to marginalise them. Furthermore its repression is a constant reminder of its existence. In this case it is an exhibitionist desire knowing no rules and therefore no consequences of exposing sexuality to 'everyone'. Following this argument, we can state an unconscious longing for the breakdown or disobeying of such rules defining what is adequate and where it is. The screening of live webcams on Cam4 showing gay sexualities combined with the possibility of interacting delivers the pornutopian solution to the mentioned repression: sexual practices, masturbation especially, are tabooed - even in 'private' communication - and associated with shame. Here they are shared by the actors and the audience. They are allowed to keep it sexual and to be seen when doing so voyeurism is highly regarded and requested.

As mentioned, gay sexuality is highly restricted by hegemonic ideas of moral standards from the public. The public character of showing private gay rooms and sexualities on Cam4 lays focus on the question how these are presented. Generally it can be stated that for the audience the factor of arousal plays an important role. Therefore gay sexualities are being shown as something desirable and therefore liveable. This effect common to gay porn movies gets intensified by the somehow more direct way of identification through the belief in authentic self-presentations. In this sense Cam4 can lead to (individual) sexual revolutions in front of the screens by its sensuous destruction of public/private-separations and its self-confident handling of gay sexualities.

Gay mainstream pornography can be seen as empowering as it creates pornutopias by gaying a heteronormative society. But in some cases it can have contrasting effects. For feature length gay porn on the internet, it can be helpful to briefly point out the concept of college porn and 'broke straight boy' porn. Both categories within gay pornography counting high numbers of viewers and clients. College porn or haze porn, as you will find on 'Dick Dorm' (2013) and 'Haze Him' (2013) also on many short cut clips on websites like XTube (2013), stage settings where heterosexual male students are forced into initiation rites consisting of sexual practices by their fellow students. The characters are shown with expressions of disgust in their faces, gay sexuality functions as a disgusting punishment. 'Broke Straight Boys' (2013) shows straight male characters being filmed by a gay cameraman and being persuaded by him with money to have sexual intercourse with each other. Having gay sex is only possible if you're broke - financially and in the sense of cajoling. While the gay cameraman somehow objectifies the straight men within the movies, he stereotypically plays the role of a gay being excluded and marginalised by homophobic straight men 
but in the same moment desiring them. College porn and broke straight boys porn present gay sexualities and subjectivities as something you are either forced or persuaded to do. In fact, besides the cameraman in the second example, gay subjectivities in the sense of being and living as gay are being kept outside of the staging.

Hetero-normative settings and homophobic resentments are being reproduced yet also transferred into the logics of gay porn. Interestingly these are logics of gay desires finally being fulfilled with anti-gay representations. In the rejection of being gay and the self-conscious reference to gay sexualities, there is gay self-hatred to be found. Coming back to Cam4, in the category 'Male' you will find an overwhelming dominance of gay interests in form of men desiring men through chat talks, commenting and, of course, showing themselves to men as well as showing other men how they fuck with men. Still the number of people defining themselves as 'straight' in their profiles is high. This is accompanied by comments and chats referring to the actors as too gay or actors' statements about themselves not being stereotypically gay. Against this background it is to ask if Cam 4 through the actors themselves intensifies gay self-hatred and if this is partially what gay men themselves desire to see.

\section{Conclusion}

Besides these examples of gay desire connected to anti-gay settings, Cam 4 can be put into the tradition of gay mainstream pornography presenting gay sexualities in a positive, identifiable way. What would anti-pornography feminists have stated on this website in general - as women present themselves voluntarily here - and how would they would argument on its huge all-male section. Recording to the radical approach of Catherine MacKinnon, she would adhere to the idea that all pornography is misogynist and therefore Cam 4 - as it is pornography - is misogynist too. One important aspect of the idea to censor pornography was the belief that it would lead to sexual violence - pornography as theory, rape as its practice. On Cam4 actually pornography is the theory and pornography is the practice. By its rather democratic way of usage, everyone can possibly show $\mathrm{him} /$ herself, watch others (simultaneously) and get in contact through this porn community. If you see porn as sexual education, Cam4 teaches on how to not only passively consume, but become a part of it for yourself.

Escoffier understood the porn theaters of the 1970s as spaces of possibility for gay men to participate rather than to stay closeted in their marginalised positions. In this way, gays could learn about their sexualities - on screen and by cruising. Cam4 makes it possible to take a look into private spaces of gay men and thereby shows and teaches what lustful everyday gay lives can look like. These private spaces become the setting for a pornutopia, where the private becomes public and gay. Furthermore the separation private/public seems to vanish as it commutes between the actors' and viewers' actual rooms and the public of the for a free and globally accessible website Cam4. This private-public sets as living spaces as well as the actual website are shown as fundamentally gay. Private spaces are gayed and not hidden to the outside world as well as the 'straight' actors, who will effectively become just one aspect of gay desire.

But it is not only the actual spaces presented via webcam that form this porn 2.0 pornutopia. Actually the whole website and its usage have to be considered. Users browse Cam4 and are browsed by others, watch webcams and get watched, masturbate while watching a live show (sometimes of themselves) and while they are clicking through the thumbnails of online webcams. It is this whole functionality to be seen as pornography. By the all-male action taking place here and the viewer's/actors taking place in it, the gaying of Cam4 means to gay a porn 2.0 community, a digital space where virtual selves get together and connected - physically at least through 
masturbating.

The link between porn and users, experienced as immediate, and the connected application of actors/viewers into the website Cam4 influences their conception of the internet in general and pornography in particular. Its specific staging of authenticity and the involvement of its users diffuses the realms of staging and reality themselves. Cam4 porns its users and they influence the modes of porning by shaping a community. From this point of view it is to ask how gay men (as well as 'straight' men) stage gay sexualities and therefore how its users porn their digital as well as real life spaces. In this sense Cam4 can have empowering as well as normative effects on gay subjectivities. Through its structural framing in the form of rating and categorising, it reproduces hierarchies of bodies and sexualities, where the non-normative is marked as the non-desirable. The ones pretty enough will win prices, while the others won't even be watched. Cam4 has to be seen in in a dynamic between normalisation and empowerment, its continual change through its users and new technological standards will go on to shape new ways of porning and therefore new possibilities to gay the world.

\section{References}

Attwood, Feona (2010), 'Younger, paler, decidedly less straight': The New Porn Professionals. In: Idem (Ed.): porn.com. Making Sense of Online Pornography. New York. pp. 88-104.

Brickell, Chris (2000) Heroes and Invaders: gay and lesbian pride parades and the public/private distinction in New Zealand media accounts. In: Gender, Place \& Culture. Edition 7, Volume 2. pp. 163-178.

Cante, Rich/Restivo, Angelo (2004) The Cultural-Aesthetic Specificities of All-male Moving-Image Pornography. In: Williams, Linda (Ed.): Porn Studies. Durham pp. 142-166.

Clarke, Kevin (2011) Porn from Andy Warhol to X-Tube. A Photographic Journey. Berlin

DeVault, Marjorie L and Gross, Glenda (2006) Feminist Interviewing. Experience, Talk and Knowledge. In: Hesse-Biber, Sharlene Nagy (Ed.): Handbook of Feminist Research. pp. 173-198.

Dietze, Gabriele and others (2007) Checks and Balances.' Zum Verhältnis von Intersektionalität und Queer Theory. In: Walgenbach, Katharina and others (Ed.): Gender als interdependente Kategorie. Neue Perspektiven auf Intersektionalität, Diversität und Heterogenität. Opladen, pp. 108-139.

Dworkin, Andrea (1987) Intercourse. New York

Escoffier, Jeffrey (2009) Bigger than Life. The History of Gay Porn Cinema from Beefcake to Hardcore. Philadelphia

Fiske, John (1996) Media Matters. Race and Gender in U.S. Politics. Minneapolis

Fung, Richard (1999) Looking for My Penis: The Eroticised Asian in Gay Video Porn. In: Gross, Larry/Woods, James (Ed.): The Columbia reader on Lesbians \& Gay men in media. New York pp. 235-253.

Gill, Rosalind (2009) Beyond the 'Sexualisation of Culture' Thesis: An Intersectional Analysis of 'Sixpacks', 'Midriffs' and 'Hot Lesbians' in Advertising. In: Sexualities. SAGE Publications, pp. 
Green, Leslie (2000) Pornographies. In: The Journal of Political Philosophy: Vol, 8., No. 1. Toronto Pp. 27-52.

Henze, Patrick (Patsy l'Amour laLove) (2009) Schwule Männlichkeit, schwuler Selbsthass, schwule Politik. Eine Tuntenperspektive zur Emanzipation. In: Hopf, Rinaldo/Schock, Axel (Ed.): Mein schwules Auge 9. Tübingen, pp. 40-46.

Kellner, Douglas (2001) Media culture: cultural studies, identity and politics between the modern and the postmodern. London

Kushner, Kaysi Eastlick/Morrow, Raymond (2003) Grounded Theory, Feminist Theory, Critical Theory. Ausgabe Toward Theoretical Triangulation. In: Advancing in Nursing Science. Ausgabe 26, Heft 1. pp. 30-43.

MacKinnon, Catharine (1993) Only Words. Cambridge

Palm, Kerstin (2007) Multiple Subjekte im Labor? Objektivismuskritik als Ausgangsbasis für interdependenztheoretische Theorie und Praxis der Naturwissenschaften. In: Walgenbach, Katharina and others (Ed.): Gender als interdependente Kategorie. Neue Perspektiven auf Intersektionalität, Diversität und Heterogenität. Opladen, pp. 141-165.

Praunheim, Rosa von (1979) Armee der Liebenden oder Aufstand der Perversen. München

Scheer, Uta (2005) Queere Monster: Repräsentationspolitik im Horrorfilm am Beispiel von Hostel (2005). In: Kraß, Andreas (Ed.): Queer Studies in Deutschland. Interdisziplinäre Beiträge zur kritischen Heteronormativitätsforschung. Berlin, pp. 239-258.

Taki, Paraskevi: Using Grounded Theory in Feminist research - A research about women's exclusion from administration positions in primary education. Available from http://freedownload.is/doc/using-grounded-theory-in-feminist-research-a-research-about$\underline{1813483 . h t m l}$

Trumann, Andrea (2004) Das bürgerliche Subjekt und sein Anderes. Zur Subjektivierung der Geschlechtscharaktere. In: Phase 2. Zeischrift gegen die Realität. Issue 13, pp. 22-24.

Williams, Linda (1995) Hard Core. Macht, Lust und die Tradition des pornographischen Films. Frankfurt am Main

Zakravsky, Katherina: Porn Chic im Web 2.0 Zeitalter. Zu ,Zack and Miri’, „Shortbus', XTube und Brent Corrigan. Essay presented at the conference 'symposium pornonom' in Vienna 2009.

\section{Audiovisual}

Boys In The Sand. Dir: Wakefield Poole. USA 1971. 90 minutes.

Deep Throat. Dir: Jerry Gerard. USA 1972. 67 minutes.

Politics Be Damned. Nova Studios. USA 1978. 16 minutes. 


\section{Internet Pornography Research}

Broke Straight Boys: Free gay porn video samples and pictures from the official site. BluMedia Network. USA 2013. http://www.brokestraightboys.com/tube/tour.php.

Cam4: Free Live Sex Webcams - Free Live Sex Chat. Surecom Corporation, NV. Curaçao 2013. Available at http://www.cam4.com

Cam4a: Cam4 Contests, Available at https://www.cam4bucks.com/aff/stats.php?page=contests

Cam4b: What You Can Earn

Available at

https://www.cam4bucks.com/aff/stats.php?page=what_3\&skin=cam4tipping\&lang=en

Cam4c: How It Works.

Available at

https://www.cam4bucks.com/aff/stats.php?page=how_3

Cam4d: About Cam4.

Available at

https://www.cam4bucks.com/aff/stats.php?page=about

Dick Dorm: Official College Orgy Site. Manwin Billing. USA 2013

Available at

http://www.dickdorm.com

Haze Him: The Official website. P3 Webtech LTD. United Kingdom 2013.

Available at

http://www.hazehim.com.

XTube: Free Porn, Sex Movies \& Porn Tube. Manwin Billing. Ireland 2013.

Available at

http://www.xtube.com

\section{Pictures}

Picture 1: http://en.cam4s.com/mattmills85

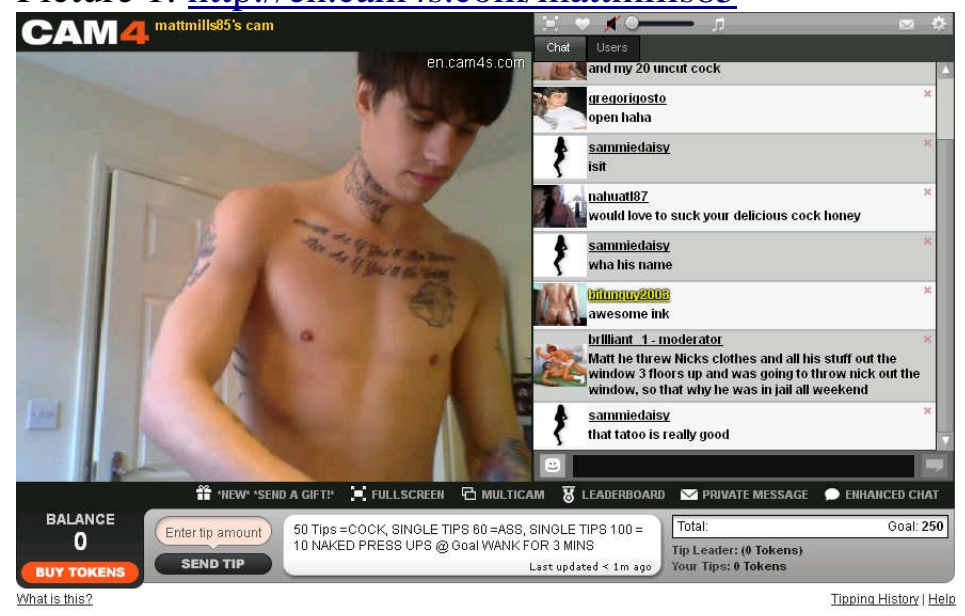

